\title{
Electrical assessment of functional lactase activity in conscious man
}

\author{
N. W. READ, R. J. DAVIES, C. D. HOLDSWORTH, AND R. J. LEVIN ${ }^{1}$ \\ From the Departments of Medicine and Physiology, University of Sheffield, Sheffield
}

SUMMARY Using an electrical technique for measuring transjejunal potential differences (PDs) in conscious man, we have estimated the electrogenic absorption of the hexoses liberated by hydrolysis of lactose which was infused into the jejunum of one normal control and 21 patients with diarrhoea. The results were compared with jejunal lactase levels determined from biopsy specimens taken from the recording site immediately after infusion. The PD evoked by $100 \mathrm{mM}$ lactose was very significantly lower in patients with lactase levels below 4 units (lactase deficient) compared with subjects with normal lactase levels. There was also a significant correlation $(r=0.87, \mathrm{P}<0.005)$ between the magnitude of the lactose potential (expressed as the ratio of the maximum glucose transfer potential) and the mucosal lactase level in the hypolactasic subjects but not in patients with normal lactase levels. Thus, in the subjects with lactase deficiency, the electrogenic transfer of hexose is clearly limited by the rate of lactose hydrolysis. Unlike other assessments of functional lactase activity, the electrical test provides a specific index of jejunal function and, moreover, can be adapted to investigate the possible disorders of small intestinal motility and secretion associated with hypolactasia.

Studies in the rat (Kohn et al.,1968) have shown that while maltose and sucrose increased the transjejunal potential difference (PD) in vitro, no change in PD occurred with lactose. Similar results have been obtained in the jejunum of the 14 week human foetus (Levin et al., 1968). These data are best explained if the transfer potential evoked by disaccharides is caused by the electrogenic transport of the hexoses released by hydrolysis. The failure of lactose to produce a transfer PD in the jejunum of the adult rat and human foetus is then presumably due to the very low lactase levels in their jejunal mucosae (Doell and Kretchmer, 1962; Dahlquist and Lindberg, 1966). It seems possible therefore that the magnitude of the lactose potential may reflect the functional lactase activity in the small intestine. We tested this hypothesis in man by comparing the transjejunal PD produced during infusion of lactose with the lactase activity estimated in a jejunal biopsy taken from the recording site immediately after infusion.

${ }^{1}$ Address for reprint requests: Dr R. J. Levin, Department of Physiology, University of Sheffield, Sheffield S10 2TN.

Received for publication 20 December 1976

\section{Methods}

Studies were undertaken on one young, healthy volunteer and 21 patients (10 male and 11 female) who were referred for jejunal biopsy with symptoms which included diarrhoea. The clinical diagnosis of each patient is given in Table 1.

\section{ELECTRICAL MEASUREMENTS}

The method for intubating the proximal jejunum and recording the PDs in conscious human subjects has been described previously (Read et al., 1974, 1976a, 1976b). The intestinal tube incorporated a biopsy capsule (Crosby and Kugler, 1957) as well as channels for the infusion and siphonage of solutions (Read et al., 1976a, 1976b). The solutions shown in Table 2 were infused into the jejunal lumen at a constant rate of $5 \mathrm{ml}$ per minute and allowed to siphon continuously from the infusion site into a receptacle at ground level. Infusion of the solution containing $100 \mathrm{mM}$ mannitol provided a baseline PD against which the transfer PDs generated by the solutions containing lactose or glucose were compared. Because of possible variations in the absolute magnitudes of the transfer PDs between patients due to differences in both electrical conductivity and 
Table 1 Clinical diagnosis and jejunal lactase levels of 21 patients with diarrhoea and of one healthy volunteer

\begin{tabular}{|c|c|c|c|c|}
\hline Patient & Sex & $\begin{array}{l}\text { Age } \\
(y r)\end{array}$ & Diagnosis & $\begin{array}{l}\text { Lactase activity } \\
\text { (Units) }\end{array}$ \\
\hline \multicolumn{5}{|c|}{ Lactase deficient } \\
\hline F.D. & $\mathbf{M}$ & 30 & Constitutional hypolactasia & 0 \\
\hline A.S. & $\mathbf{M}$ & 18 & Constitutional hypolactasia & 0 \\
\hline E.E. & $\mathbf{F}$ & 56 & Coeliac disease, lyphoma & 0 \\
\hline R.K. & $\mathbf{M}$ & 53 & Tuberculosis, treated with isoniazid & 0.6 \\
\hline J.E. & $\mathbf{M}$ & 34 & Total colitis, colectomy & 0.4 \\
\hline G.M. & $\mathbf{M}$ & 59 & Post-gastrectomy diarrhoea & $1 \cdot 2$ \\
\hline E.H. & $\mathbf{F}$ & 70 & Anaemia, diarrhoea & $2 \cdot 0$ \\
\hline J.M. & $\mathbf{F}$ & 31 & Coeliac disease & $2 \cdot 4$ \\
\hline E.B. & $\mathbf{F}$ & 36 & Total colitis, colectomy hypopituitarism & $2 \cdot 6$ \\
\hline B.W. & $\mathbf{F}$ & 33 & Coeliac disease & $3 \cdot 7$ \\
\hline \multicolumn{5}{|c|}{ Normal lactase activity } \\
\hline T.B. & $\mathbf{M}$ & 70 & Distal colitis & $6 \cdot 7$ \\
\hline J.S. & $\mathbf{M}$ & 46 & Irritable bowel syndrome & $8 \cdot 0$ \\
\hline C.H. & $\mathbf{F}$ & 69 & Pernicious anaemia, diarrhoea & $8 \cdot 2$ \\
\hline M.W. & $\mathbf{F}$ & 23 & Irritable bowel syndrome & $8 \cdot 4$ \\
\hline D.B. & $\mathbf{F}$ & 42 & Anaemia, hyposplenism, visual failure & $\mathbf{9 \cdot 2}$ \\
\hline C.H. & $\mathbf{F}$ & 21 & Normal control & $\mathbf{9 \cdot 6}$ \\
\hline D.B. & $\mathbf{F}$ & 76 & Megaloblastic anaemia, osteomalacia & $9 \cdot 8$ \\
\hline L.M. & $\mathbf{M}$ & 70 & Distal colitis, hypertension, carcinoma of bronchus & $10 \cdot 0$ \\
\hline D.F. & $\mathbf{F}$ & 14 & Irritable bowel syndrome & $10 \cdot 4$ \\
\hline G.D. & $\mathbf{F}$ & 51 & Purgative abuse & $12 \cdot 3$ \\
\hline B.M. & $\mathbf{M}$ & 75 & Post-gastrectomy diarrhoea & $13 \cdot 0$ \\
\hline A.M. & $\mathbf{M}$ & 78 & Tuberculosis, renal failure, weight loss, anaemia & $14 \cdot 5$ \\
\hline
\end{tabular}

The subjects, arranged in ascending order of their lactase activities, fall into two groups; those with lactase activities below 4 units (lactase deficient) and those with lactase activities above 6 units (normal). Although only two patients in the lactase deficient group have been diagnosed as constitutional hypolactasics, it is nevertheless possible that other patients in this group have constitutional hypolactasia in addition to the stated diagnosis.

Table 2 Solutions infused into jejunal lumen

Solution $1 \quad 104 \mathrm{mM} \mathrm{NaCl}+100 \mathrm{mM}$ mannitol

Solution $2 \quad 104 \mathrm{mM} \mathrm{NaCl}+100 \mathrm{mM}$ glucose

Solution $3 \quad 104 \mathrm{mM} \mathrm{NaCl}+100 \mathrm{mM}$ mannitol

Solution $4 \quad 104 \mathrm{mM} \mathrm{NaCl}+100 \mathrm{mM}$ lactose

the current induced by ion-linked hexose transfer, the potentials evoked by $100 \mathrm{mM}$ lactose were normalised by being expressed as a ratio of the transfer potential generated by $100 \mathrm{mM}$ glucose. This concentration was employed because it saturated the electrogenic glucose transport mechanism, thus avoiding problems in interpretation caused by possible differences in 'apparent $\mathrm{Km}$ ' between patients.

\section{ESTIMATIONS OF LACTASE ACTIVITY}

Before the intestinal tube was finally withdrawn a specimen of jejunal mucosa was obtained by means of the biopsy capsule. The biopsy was detached from the capsule, spread mucosa upwards on a clean piece of blotting paper, and divided into two portions with a sharp scalpel. One portion was immersed in formalin and sent for routine histology, while the other was assayed for lactase activity by a modification of the method described by Burgess et al. (1964). Briefly, this consisted of incubating a homogenate of the biopsy with $40 \mathrm{mM}$ lactose for 20 minutes and then estimating the glucose liberated, using the glucose oxidase method (Boehringer Test Kit; catalogue number 15756). The results were expressed as lactase units where 1 unit $=1 \mu \mathrm{mol}$ lactase split $/ \mathrm{g}$ of tissue wet weight ${ }^{-1}$ minute $^{-1}$.

\section{Results}

The lactase activities for the subjects included in this study cluster into two groups (Table 1); those below 4 units (range 0-3.7 units) and those above 6 units (range 6.6-14.5 units). The normal range for lactase activity reported by different authors varies widely, but our upper group appears to correspond approximately with the normal ranges of McMichael et al. (1966) (3.4-18.6 units) and Preston (1970) (4.0-12.5 units), who have both used the same method for lactase assay described in this present paper. We have thus classified all of our patients with lactase activity below 4 units as being lactase deficient. It can be seen from Table 1 that these are a heterogeneous group, containing patients in whom hypolactasia may be secondary to another condition such as coeliac disease as well as two subjects with alactasia for which there was no obvious cause. It was interesting that these two patients, who have been credited with the diagnosis of constitutional 
Fig. 1 The PD evoked by $100 \mathrm{mM}$ lactose (dotted bars) and the PD generated by $100 \mathrm{mM}$ glucose (open bars) in subjects with normal lactase levels and patients with lactase deficiency (see Table 1). The results are expressed as the mean \pm SEM.

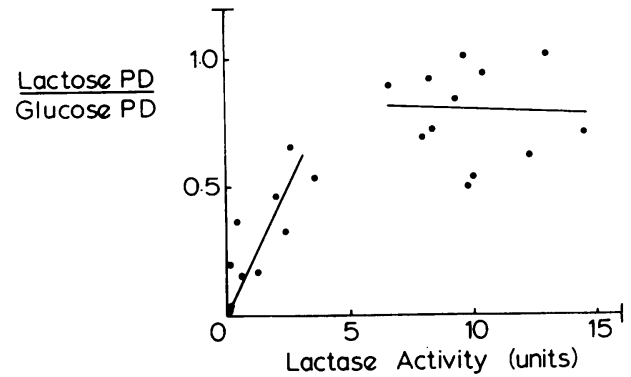

Fig. 2 A graph of the lactose potential expressed as a ratio of the glucose transfer potential (see methods) plotted against the lactase activity in the biopsy specimens. The regression lines have been inserted for the groups with lactase deficiency and normal lactase activity. There is a significant correlation $(\mathrm{r}=0 \cdot 87$, $\mathrm{P}<0.005)$ between the ratio of the potentials and the mucosal lactase levels in the patients with lactase deficiency but not in those with normal lactase levels.

hypolactasia, were the only subjects to have no demonstrable lactose potential.

It can be seen from Fig. 1 that the lactose potentials from the lactase deficient group are significantly lower than the corresponding values from the group with normal lactase activities, while the glucose potentials are not significantly different. If the lactose transfer potential, expressed as a ratio of the glucose PD is plotted against the lactase activity (Fig. 2) then there is a highly significant correlation $(r=0.87, \mathrm{P}<0.005)$ between the two sets of data in the subjects with lactase deficiency. However, in

those patients with normal lactase activity the correlation is not significant $(r=0.06)$, the slope of the regression line being very close to zero.

\section{Discussion}

The results of this study clearly indicate that, in patients with lactase deficiency, including three with coeliac disease, the electrogenic uptake of hexose from lactose is limited by the rate of lactose hydrolysis. As such, they confirm and extend the findings of McMichael et al. (1967) who used perfusion studies in which the uptake of hexose from lactose infused into the human jejunum was estimated chemically. Measurement of absorption by these perfusion techniques is, however, subject to considerable errors when absorption is very depressed (Holdsworth and Dawson, 1965), which presumably accounts for the absence of published data on the variations in hexose absorption from lactose within the hypolactasic group. With the electrical technique it is possible to obtain a definitive index of active hexose absorption even when this is low and thus we have been able to demonstrate a significant correlation between the electrogenic transfer of hexoses and the mucosal lactase levels in patients with lactase deficiency (Fig. 2).

Although most of the tests available for the clinical determination of hypolactasia are noninvasive, they provide only indirect estimates of the functional lactase activity of the intestinal mucosa. The lactose tolerance test depends on the functional integrity of the liver, pancreas and kidneys, while the more recent breath tests (Sasaki et al., 1970; Bond and Levitt, 1972) require relatively normal intestinal motility and respiratory function and appropriate colonic bacteria. Even the estimation of lactase levels in biopsy specimens may not provide a true index of functional activity because of possible differences between the lactase activity in homogenates and intact brush border (Zoppi et al., 1966). The measurement of the transfer PDs from the hydrolysis products of lactose, while providing an index of the functional lactase activity of the jejunal mucosa in $s i t u$, is, at the present, a research technique rather than a routine clinical test. Although an intrusive method, it can be easily undertaken during the procedure for jejunal biopsy. Moreover, the recording of the PD can also be adapted for the electrical investigation of the putative secretory activity of the small intestine associated with motility (Read et al., 1976c). This could provide a new research approach to investigate the pathophysiology of diarrhoea and abdominal discomfort associated with hypolactasia.

We would like to thank Dr F. E. Preston for his 
assistance in the preparation of this study and A. J. Parker (LIBiol) for drawing the Figures.

\section{References}

Bond, J. H., and Levitt, M. D. (1972). Use of pulmonary hydrogen $\left(\mathrm{H}_{2}\right)$ measurements to quantitate carbohydrate absorption: study of partially gastrectomized patients. Journal of Clinical Investigation, 51, 1219-1225.

Burgess, E. A., Levin, B., Mahalanabis, D., and Tonge, R. E. (1964). Hereditary sucrose intolerance; levels of sucrase activity in jejunal mucosa. Archives of Diseases in Childhood, 39, 431-443.

Crosby, W. H., and Kugler, H. W. (1957). Intraluminal biopsy of the small intestine; the intestinal biopsy capsule. American Journal of Digestive Diseases, 2, 236-241.

Dahlqvist, A., and Lindberg, T. (1966). Development of the intestinal disaccharidase and alkaline phosphatase activities in the human foetus. Clinical Science, 30, 517-528.

Doell, R. G., and Kretchmer, N. (1962). Studies of small intestine during development. I. Distribution and activity of $\beta$-galactosidase. Biochimica et Biophysica Acta, 62, 353362.

Holdsworth, C. D., and Dawson, A. M. (1965). Glucose and fructose absorption in idiopathic steatorrhoea. Gut, 6, 387391.

Kohn, P. G., Smyth, D. H., and Wright, E. M. (1968). Effects of amino acids, dipeptides and disaccharides on the electrical potential across rat small intestine. Journal of Physiology, 196, 723-746.

Levin, R. J., Koldovský, O., Hošková, J., Jirsová, V., and Uher, J. (1968). Electrical activity across human foetal small intestine associated with absorption processes. Gut, 9, 206-213.

McMichael, H. B., Webb, J., and Dawson, A. M. (1966). Jejunal disaccharidases and some observations on the cause of lactase deficiency. British Medical Journal, 2, 10371041.

McMichael, H. B., Webb, J., and Dawson, A. M. (1967). The absorption of maltose and lactose in man. Clinical Science, 33, 135-145.

Preston, F. E. (1970). Jejunal Disaccharidases; their Histopathological and Clinical Significance. Thesis: University of Liverpool.

Read, N. W., Barber, D. C., Levin, R. J., and Holdsworth, C. D. (1976a). The unstirred layer and kinetics of electrogenic glucose absorption in the human jejunum in situ. (Submitted for publication to Gut.)

Read, N. W., Holdsworth, C. D., and Levin, R. J. (1974). The electrical measurement of intestinal absorption of glucose in man. Lancet, 2, 624-627.

Read, N. W., Levin, R. J., and Holdsworth, C. D. (1976b). Electrogenic glucose absorption in untreated and treated coeliac disease. Gut, 17, 444-449.

Read, N. W., Smallwood, R. H., Levin, R. J., Holdsworth, C. D., and Brown, B. H. (1976c). The relationship between changes in intraluminal pressure and transmural potential difference in the human and canine jejunum in vivo. Gut, 18, 141-151.

Sasaki, Y., Iio, M., Kameda, H., Ueda, H., Aoyagi, T., Christopher, N. L., Bayless, T. M., and Wagner, H. N. (1970). Measurement of ${ }^{14} \mathrm{C}$-lactose absorption in the diagnosis of lactase deficiency. Journal of Laboratory and Clinical Medicine, 76, 824-835.

Zoppi, G., Hadorn, B., Gitzelmann, R., Kistler, H., and Prader, A. (1966). Intestinal $\beta$-galactosidase activities in malabsorption syndromes. Gastroenterology, 50, 557-561. 